\title{
Os think tanks dos Estados Unidos e a produção de ideias sobre o Brasil como país emergente, 2000- 2016
}

\author{
$\overline{\text { Eduardo Munhoz Svartman }^{1} \text { (i) }}$
}

$\mathrm{O}$ artigo analisa as representações produzidas pelos think tanks estadunidenses a respeito do Brasil entre 2000 e 2016, período de maior protagonismo externo brasileiro e cuja projeção internacional representou um desafio epistêmico para o establishment de Washington. Para tanto, descreveu-se o panorama institucional no qual essa produção ideacional foi articulada e difundida nos Estados Unidos e empregou-se a metodologia da análise de conteúdo para investigar essas publicações e as entrevistas realizadas com atores que operam nesse ambiente. Argumenta-se que essa produção alimentou uma narrativa de valores compartilhados na qual o Brasil agiria de forma convergente com os EUA na divisão dos custos de manutenção da ordem em regiões como a América do Sul e a África Ocidental. Contudo, o dissenso quanto ao princípio de soberania e o papel dos Brics, bem como a retração da política externa, acentuada pela crise doméstica brasileira, engendraram também uma narrativa que enfatiza a desconfiança quanto às capacidades brasileiras e a decepção quanto ao seu protagonismo externo.

Palavras-chave: países emergentes; think tanks; Brasil; relações Brasil-Estados Unidos

\section{Introdução ${ }^{2}$}

As primeiras décadas do século XXI acumularam mudanças importantes no sistema internacional. Os Estados Unidos, que desde o fim da Guerra Fria ocupavam posição de excepcional concentração de poder, sofreram abalos importantes com os atentados de 11 de setembro de 2001, os desgastes fiscal e de legitimidade decorrentes da "Guerra Global ao Terror" e a recessão que sucedeu à crise financeira de 2008. Enquanto isso, a Rússia retomou o seu protagonismo externo e a China alcançou o patamar de segunda maior economia do mundo. Paralelamente, países como África do Sul, Brasil, Índia, Indonésia e Turquia, impulsionados por elevadas taxas de crescimento, assumiram posições mais

\footnotetext{
1 Universidade Federal do Rio Grande do Sul, Departamento de Ciência Política. Porto Alegre (RS), Brasil. Email: <eduardosvartman@gmail.com>.

2 Esta pesquisa contou com financiamento da Capes, processo 001583/2015-08, à qual sou imensamente grato. Agradeço também as contribuições dadas pelos(as) pareceristas que avaliaram este artigo.
} 
assertivas em diversos foros multilaterais, desenhando novas coalizões (Brics, G-20, Ibas) ${ }^{3}$ que refletiram uma parcial redistribuição do poder econômico e político no sistema (Hurrell, 2006; Kahler, 2013; Pecequilo, 2012).

No caso específico do Brasil, o país viveu um ciclo, em sua ação externa, que partiu da crítica aos custos do processo de globalização, ainda nos anos finais do governo Fernando Henrique Cardoso, e avançou em direção à maior diversificação e busca por autonomia na administração Luiz Inácio Lula da Silva. Sua operacionalização se dava através da construção de coalizões em organizações internacionais, da criação de novos foros regionais, da mobilização de um discurso reformista dos organismos internacionais ou da projeção econômica e política sobre América do Sul, África e Oriente Médio (Vigevani e Cepaluni, 2007). A isso se somaram os programas de modernização das suas forças armadas a partir da produção doméstica de sistemas de armas em cooperação com parceiros europeus (Villa e Viana, 2010). Posteriormente, nos governos Dilma Rousseff, esse ciclo se retraiu para níveis mais baixos de protagonismo e, no governo Michel Temer, sofreu uma inflexão, abandonando o discurso reformista, distanciando-se da África e assumindo uma postura voltada à busca de acordos de livre comércio com a Europa e os Estados Unidos (Saraiva, 2014; Svartman e Silva, 2016).

Em resposta à crise doméstica e às mudanças externas, de 2009 a 2016, a estratégia dos Estados Unidos foi mais inclusiva (ao menos discursivamente) e menos intrusiva, o que, de fato, concedeu mais espaço para o Brasil e demais países agirem. Os principais objetivos dos Estados Unidos consistiam em recuperar a imagem do próprio país (e da ordem que lidera desde 1945), enfatizando o multilateralismo e a divisão dos custos de sua manutenção com outros países com os quais partilhassem certo leque de valores e interesses (Pecequilo, 2012).

Tal estratégia não foi, contudo, consensual, e o governo Donald Trump e seu slogan "America First" são um forte indicador disso. Há intenso debate interno nos EUA sobre o seu papel como potência central, a melhor conduta a assumir e o que representariam individualmente e em grupo os chamados países emergentes. Essa discussão perpassa tanto o meio acadêmico (Ikenberry, 2011; Mearsheimer, 2014; Posen, 2014) quanto a opinião pública (expressa na mídia e nas sondagens de opinião) e se inter-relaciona com as clivagens do meio político estadunidense. Nesse ambiente, os think tanks desempenham papel ativo, promovendo narrativas, divulgando agendas e "soluções" e exercendo a função de tradução de informações, dados e fenômenos do conhecimento dos chamados policy experts ou especialistas (sejam acadêmicos ou não) para os atores responsáveis pela formulação e implementação de políticas públicas: políticos do Executivo e do Legislativo e quadros da burocracia governamental (Departamento de Estado,

\footnotetext{
3 Brics é o acrônimo do grupo integrado por Brasil, Rússia, Índia, China e África do Sul formado em 2006. G-20 é um bloco de países em desenvolvimento criado em 2003 no âmbito da Organização Mundial do Comércio. Ibas é o acrônimo do Fórum de Diálogo Índia-Brasil-África do Sul, criado em 2003.
} 
Departamento de Defesa etc.), e para o público geral. Tudo isso, com vistas a moldar as políticas doméstica e externa dos Estados Unidos (Abelson, 2006).

Diante de tal conjuntura, este artigo analisa quais são as representações produzidas pelos think tanks estadunidenses a respeito do Brasil durante o período de maior protagonismo externo brasileiro. Argumenta-se que o crescimento econômico e maior ativismo internacional do Brasil representaram um desafio epistêmico para o establishment de Washington. Num ambiente de mudança na distribuição de poder no sistema internacional e de crise nos Estados Unidos, os chamados países emergentes, entre eles o Brasil, suscitaram uma série de estudos a respeito de suas políticas externa e de defesa, além de suas características domésticas e de como esses países afetariam positiva ou negativamente interesses estadunidenses.

No decorrer do período, vários think tanks se engajaram na tarefa de produzir narrativas a respeito do Brasil e, assim, influenciar a produção ideacional que informa o entendimento e a formulação de políticas dos EUA no que se refere ao Brasil. Essa produção procurou compreender o papel que o país desempenharia no cenário pós-unipolar e alimentou a expectativa de que ele agiria de forma convergente com os Estados Unidos na divisão dos custos de manutenção da ordem em regiões como América do Sul e África Ocidental. O dissenso quanto ao significado de determinados princípios e a retração da política externa, acentuada pela crise doméstica brasileira, engendraram também uma narrativa que enfatiza desconfiança quanto às capacidades brasileiras e decepção quanto ao seu protagonismo.

As fontes utilizadas neste estudo consistem em relatórios mais extensos e livros publicados pelos think tanks selecionados, artigos publicados em periódicos e geralmente reproduzidos nos sites dos próprios think tanks e entrevistas em profundidade conduzidas com pesquisadores, diretores de programas e autores de textos, todos vinculados aos think tanks investigados ${ }^{4}$. Esse material foi tratado empregando-se técnicas de análise de conteúdo com vistas a apreender a produção ideacional predominante entre os think tanks de Washington a respeito das políticas externa e de defesa nacional do Brasil entre 2000 e 2016. A seleção dos think tanks se deu por meio de um processo de aproximações sucessivas com base na literatura especializada e na existência de programas e/ou produção de artigos, relatórios e eventos dedicados ao Brasil, e através da interação com os entrevistados.

Para demonstrar o argumento anteriormente apresentado, a pesquisa será relatada da seguinte forma: esta Introdução; a apresentação das definições teóricas e conceituais utilizadas e uma pequena cartografia dos think tanks investigados; a análise da narrativa benevolente a respeito dos valores compartilhados com os Estados Unidos e da expectativa de atuação "construtiva" do Brasil na ordem liberal; a análise dos pontos

\footnotetext{
${ }^{4}$ As entrevistas estão disponíveis no site do Cesop na página deste artigo, na seção Revista Opinião Pública: <https://www.cesop.unicamp.br/por/opiniao_publica>.
} 
OS THINK TANKS DOS ESTADOS UNIDOS E A PRODUÇÃO DE IDEIAS SOBRE O BRASIL COMO PAÍS EMERGENTE, 2000-2016

de dissenso, desconfiança e decepção da produção dos think tanks; e, por fim, as Considerações Finais.

\section{Definição conceitual e panorama dos think tanks investigados}

A literatura acadêmica sobre os think tanks é relativamente recente e uma de suas principais características é a dificuldade de definir conceitualmente o seu objeto de investigação. Eventualmente, essas definições são construídas a partir da narrativa histórica das "gerações" de think tanks, ou em oposição a outras instituições mais investigadas, como fundações, institutos de pesquisa, empresas de consultoria, grupos de interesse ou escritórios de lobby. Esse traço decorre das diferentes atividades realizadas pelos think tanks e da história do desenvolvimento dessas instituições dedicadas a influenciar o debate e o processo político, com base no princípio de legitimidade da expertise. Organizações muito diferentes são rotuladas como think tanks e a expressão é, com frequência, aplicada de forma anacrônica (Medvetz, 2012).

Os primeiros estudos na área vêm da tradição crítica de pesquisa a respeito das elites nos Estados Unidos (Domhoff, 1967). Maior atenção passou a ser dedicada aos think tanks depois da sua expansão numérica e maior visibilidade nos anos 1980, quando emergiu uma literatura que os analisa como atores sociais operando no sistema político (Smith, 1991; Ricci, 1994). Desde então, há uma pluralidade de abordagens que enfatizam a dimensão institucional dos think tanks (McGann e Sabatini, 2011; Abelson, 2006), ou que os descrevem como comunidades epistêmicas (Stone, 1996). Os think tanks estadunidenses são organizações privadas sem fins lucrativos, cujas receitas provêm, majoritariamente, de doações privadas ou contratos com agências governamentais. Desempenham diferentes atividades no chamado "mercado de ideias", que envolvem desde recomendações para governantes e legisladores, promoção de agendas políticas, networking, até divulgação midiática. Parte significativa de seus quadros ocupa, ao longo de suas carreiras, posições no governo (ou assessoria parlamentar), em empresas, em organizações multilaterais ou na academia, conformando o fenômeno informalmente chamado de "porta giratória".

Em função dessas características, entende-se que, conforme Medvetz (2012), os think tanks constituem um espaço social no qual as lógicas e demandas do mundo da política, dos negócios, da mídia e da academia estão em operação ao mesmo tempo, e sua produção discursiva tem função importante na forma pela qual os atores daqueles distintos campos enquadram problemas específicos e as políticas a esses problemas direcionadas.

Há estudos que demonstram, empírica (Parmar, 2004) e teoricamente (Legro, 2009), de que maneira organizações hoje classificadas como think tanks, em diferentes circunstâncias, desempenharam papéis ativos na elaboração de consensos entre elites, na mobilização da opinião pública e na condução de uma diplomacia extraoficial em torno de 
determinados temas de política externa e, assim, contribuíram para a mudança nas ideias que informavam as opções políticas dos Estados Unidos.

Considera-se aqui que os think tanks operam participando do processo de construção ideacional dos chamados interesses nacionais dos Estados Unidos, envolvendo, assim, a definição de quem seriam seus aliados e parceiros e o que esperar de seus adversários, reais ou potenciais. A produção ideacional dos think tanks está firmemente engajada na construção de identidades e significados a respeito do papel dos EUA e dos países emergentes. O foco desta investigação não está nas organizações em si (embora não sejam desconsideradas), mas na sua produção ideacional a respeito do Brasil, em que predominam variantes da "tradição liberal" que informam tanto as vertentes realistas quanto as idealistas de entendimento da política externa dos EUA (Zahran, 2012). É importante frisar que essa produção tende a naturalizar o que chamam de ordem liberal, construída e liderada pelos EUA desde 1945 como um bem comum universal ${ }^{5}$. A questão fundamental que informa a produção dos experts em Brasil e demais emergentes é: em que medida esses países pretendem ser acomodados na ordem liberal e em que medida eles são forças que desafiam a ordem e pretendem modificá-la ou criar outra. Para avançar na análise da produção ideacional a respeito do Brasil, é necessário, contudo, definir quais think tanks efetivamente se dedicaram a isso e como eles se situam no ambiente de Washington.

Convém salientar que o Brasil não é um tema central na agenda dos think tanks estadunidenses; o país não tem a visibilidade dos temas prioritários para as políticas externa e de defesa dos EUA, como terrorismo, Oriente Médio, China, narcotráfico ou imigração. Por isso, há apenas um programa dedicado exclusivamente ao Brasil (no Woodrow Wilson International Center for Scholars), e o país geralmente é objeto de interesse de forma episódica nos programas da América Latina e, mais recentemente, naqueles sobre países emergentes. Embora os programas regionais priorizem México, Colômbia e Cuba e os dedicados aos emergentes estejam mais interessados na China e na Rússia, foi possível identificar um grupo de think tanks que esteve de fato engajado na produção de policy analysis a respeito do Brasil e da sua ação internacional desde o início dos anos $2000^{6}$.

Trata-se de 11 think tanks; nem todos dedicaram a mesma atenção ao Brasil e tampouco o fizeram da mesma forma. Antes de a investigação adentrar no conteúdo dessa

\footnotetext{
${ }^{5}$ Entre os aspectos dessa ordem liberal enfatizados pelos think tanks estudados, estão o livre comércio, as organizações internacionais como ONU, FMI e Banco Mundial, a segurança cooperativa, a democracia e o rule of law. O caráter hierárquico de tal ordem (Ikenberry, 2011), as assimetrias entre centro e periferia, a posição privilegiada que nela os EUA ocupam (Vezirgiannidou, 2013) e o fato de que ela traduz interesses e valores particulares dos EUA como universais (Zahran, 2012) tendem a ser temas obliterados pelas policy analysis dos think tanks.

6 É importante salientar que há décadas o Brasil é objeto de interesse diplomático, midiático e acadêmico nos Estados Unidos, expresso na elevação das representações diplomáticas ao nível de embaixada em 1905, na presença continuada de correspondentes de imprensa e na produção acadêmica expressiva a ponto de existir uma associação de especialistas desde 1992, a Brazilian Studies Association.
} 
produção, eles serão analisados coletivamente, de modo a estabelecer uma pequena "cartografia" daqueles que produziram representações a respeito do Brasil. Assumindo-se a tese de Medvetz (2012), de que os think tanks estadunidenses estão subordinados simultaneamente às lógicas de quatro campos distintos (econômico, político, acadêmico e midiático), os think tanks analisados são aqui divididos em grupos segundo a sua maior afinidade relativa a cada um desses campos. Cabe salientar que, embora o think tank possa se aproximar mais das regras e disposições de um dos determinados campos, ele não rompe com os demais. Assim, entre os que se aproximam mais do campo econômico, tem-se o Brazil Institute do Wilson Center for International Scholars, o The Inter-American Dialogue, o Atlantic Council, o Center for Strategic International Studies (CSIS) e, por fim, o American Enterprise Institute (AEI). Mais próximos do campo político, particularmente do Executivo, têm-se o Council on Foreign Affairs (CFR), o Center for American Progress (CAP), o Center for Naval Analysis (CNA) e o Institute for National Strategic Studies (INSS) da National Defense University. Mais inclinados a priorizar as práticas acadêmicas, têm-se o Carnegie Endowment for International Peace e a Brookings Institution. Nenhuma das organizações investigadas se pauta majoritariamente pelas regras do campo midiático; contudo, todas têm estratégias muito bem desenhadas de comunicação e de inserção de seus especialistas nas mídias impressa, televisiva e online. O Quadro 1 sistematiza a divisão adotada.

\section{Quadro 1}

Classificação dos think tanks por afinidade relativa

\begin{tabular}{|l|c|c|}
\hline Campo econômico & Campo político & Campo acadêmico \\
\hline Brazil Institute/Wilson Center & Council on Foreign Affairs (CFR) & $\begin{array}{c}\text { Carnegie Endowment for } \\
\text { International Peace }\end{array}$ \\
\hline The Inter-American Dialogue & Center for American Progress (CAP) & Brookings Institution \\
\hline Atlantic Council & Center for Naval Analysis (CNA) & \\
\hline $\begin{array}{l}\text { Center for Strategic International } \\
\text { Studies (CSIS) }\end{array}$ & $\begin{array}{c}\text { Institute for National Strategic } \\
\text { Studies (INSS) - National Defense } \\
\text { University }\end{array}$ & \\
\hline American Enterprise Institute (AEI) & & \\
\hline
\end{tabular}

Fonte: Elaboração própria.

Há certa arbitrariedade em tal divisão, contudo, considerando a origem do financiamento, perfil da produção e dos especialistas, perfil dos eventos organizados e membros do board, é possível estabelecer essa distinção analítica. Novamente, afirmar que um think tank tem maior afinidade com um determinado campo não quer dizer que ele esteja desconectado dos demais, indica apenas que as características de um campo são mais acentuadas que as dos outros.

Embora o Brasil seja um país que receba relativamente pouca atenção dos think tanks de Washington, as organizações que publicaram produção significativa de relatórios, artigos e livros ou que promoveram eventos a respeito da atuação internacional do Brasil são aquelas percebidas como mais relevantes. Periodicamente, a Universidade da 
Pensilvânia publica um ranking que classifica think tanks do mundo inteiro, o Global Go Think Tanks Index Report. Trata-se, basicamente, de um instrumento de aferição de reputação através de surveys junto a 6.500 instituições dessa natureza aproximadamente e a mais de 7.500 jornalistas, doadores, políticos e especialistas que, em diferentes países, se envolvem com policy analysis (McGann, 2016). Como se pode observar na Tabela 1, do universo de 1.830 think tanks estadunidenses ranqueados, os aqui investigados figuram claramente entre os primeiros.

Tabela 1

Posição no "top think tanks" dos Estados Unidos

\begin{tabular}{|l|c|}
\hline Classificação & Organização \\
\hline 1 & Brookings Institution \\
\hline 2 & Council on Foreign Affairs (CFR) \\
\hline 3 & Center for Strategic International Studies (CSIS) \\
\hline 4 & Carnegie Endowment for International Peace \\
\hline 5 & Brazil Institute/Wilson Center \\
\hline 11 & Center for American Progress (CAP) \\
\hline 14 & American Enterprise Institute (AEI) \\
\hline 34 & Atlantic Council \\
\hline 85 & The Inter-American Dialogue \\
\hline- & Center for Naval Analysis (CNA) \\
\hline
\end{tabular}

Fonte: Elaboração com base em McGann (2016).

É possível caracterizar os think tanks aqui abordados como, majoritariamente, instituições de grande porte no seu universo. Apenas dois possuem um staff inferior a 100 pessoas, o The Inter-American Dialogue, um dos poucos think tanks de Washington exclusivamente voltados para a América Latina, e o INSS, que, embora tenha um número pequeno de pessoas permanentemente envolvidas, conta com a estrutura da National Defense University, instituição por onde circula um grande número de militares e civis dos EUA e de outros países. Os orçamentos anuais também estão, na maioria, entre os mais expressivos dos EUA. Apenas o The Dialogue e o INSS operam na faixa inferior aos US\$ 10 milhões ao ano. Doações privadas (de empresas, indivíduos e fundações) são a principal fonte de recursos ${ }^{8}$, exceto para o Carnegie Endowment for International Peace, que conta com um fundo que lhe assegura parte do orçamento anual, para o CNA, cuja receita é provida por contratos com a Marinha dos EUA, e para o INSS, que é parte do Departamento de Defesa.

\footnotetext{
7 Por ser um instituto da "universidade corporativa" do Departamento de Defesa, o INSS não é listado, a despeito de seu impacto no setor de defesa.

8 O universo dos think tanks nos Estados Unidos é dominado por organizações da sociedade civil sem fins lucrativos consideradas de interesse público, que estão habilitadas a receber doações privadas dedutíveis do imposto de renda de seus doadores.
} 
Tabela 2

Orçamento e pessoal

\begin{tabular}{|l|c|c|}
\hline Organização & Orçamento (US\$ Mi) & Staff $^{\mathbf{9}}$ \\
\hline Brookings Institution & 95,5 & 369 \\
\hline $\begin{array}{l}\text { Center for Strategic International Studies } \\
\text { (CSIS) }\end{array}$ & 32,3 & 220 \\
\hline Council on Foreign Affairs (CFR) & 77,4 & 302 \\
\hline Wilson Center & 15 & 136 \\
\hline Center for American Progress (CAP) & 45,1 & 236 \\
\hline American Enterprise Institute (AEI) & 54,6 & 225 \\
\hline Atlantic Council & 20,9 & 224 \\
\hline Carnegie Endowment for International & 48 & 161 (nos EUA) \\
\hline Peace & 2,9 & 26 \\
\hline The Inter-American Dialogue & 119,4 & 372 \\
\hline Center for Naval Analysis (CNA) & 6,9 & 14 \\
\hline INSS/National Defense University & & . \\
\hline
\end{tabular}

Fonte: Elaboração própria com base nos relatórios e informações disponibilizados nos sites dos think tanks.

Para se ter uma compreensão mais precisa do panorama dos think tanks, serão descritas mais detalhadamente três instituições, cada uma com maior afinidade com um dos campos anteriormente descritos. Entre os think tanks mais próximos do campo econômico, destaca-se o Brazil Institute do Woodrow Wilson International Center for Scholars. O Wilson Center, como é mais conhecido, foi criado em 1968 como um living memorial do presidente Woodrow Wilson; atualmente abriga 11 centros ou programas "globais" e 15 "regionais". Para o continente americano, sedia um instituto para a América Latina, um para o Canadá, um para o México e um para o Brasil, este financiado apenas com doações privadas. Como foi visto, o Wilson Center é considerado um dos mais relevantes think tanks dos Estados Unidos, de acordo com os critérios estabelecidos por McGann (2016). O Brazil Institute partilha dessa apreciação e é frequentemente referido pelos entrevistados da pesquisa aqui relatada entre os think tanks mais importantes no que diz respeito a temas que envolvem o Brasil.

Criado em 2006, o Brazil Institute foi desdobramento de um programa implantado no ano 2000, destinado a criar uma "presença" do Brasil em Washington, chamando a atenção dos policymakers estadunidenses (Wilson Center, 2002). De acordo com Luis Bitencourt, diretor da iniciativa até 2005, o programa surgiu, de um lado, em razão do maior interesse a respeito do Brasil, decorrência de seu "bom desempenho" e "relevância" e, de outro, da ação do embaixador Rubens Barbosa, que, para Bitencourt,

(...) entendeu como funciona Washington. E percebeu o seguinte: Você pode divergir em muita coisa dos norte-americanos, da política americana, mas se você não encontrar espaço para tentar influenciar isso, de nada adianta você

\footnotetext{
${ }^{9}$ Foram computados tanto os pesquisadores quanto os gestores e pessoal de apoio. Alguns think tanks são também membership organizations, espécie de clube cuja lista de membros pode ser bastante extensa (o CFR possui milhares de membros, individuais e corporativos), nesse caso, optou-se por contabilizar como staff apenas as pessoas que exerceram funções diretas no think tank, conforme descrito no último relatório disponível.
} 
ficar aborrecido. (...) se você entender como funcionam os mecanismos aqui, você pode beneficiar o Brasil. Então ele, com uma atividade extremamente dinâmica, procurou vários think tanks ${ }^{10}$.

No seu primeiro período, o programa obteve fundos de empresas como Texaco, ADM, Cargil e GE Fund e do Ministério da Cultura do Brasil, do qual obteve bolsas para manter três pesquisadores brasileiros em temporadas de curta duração (Wilson Center, 2002). Segundo Paulo Sotero, diretor do Brazil Institute desde 2006, o interesse sobre o Brasil se renovou com a eleição de Luiz Inácio Lula da Silva, o que também contribuiu para que o programa assumisse o status de instituto ${ }^{11}$.

Mais recentemente, o foco do Brazil Institute está nas relações bilaterais entre Estados Unidos e Brasil, e seus temas prioritários são questões econômicas e sociais; ciência, tecnologia e inovação; estado de direito (rule of law); e mudança climática. Com um orçamento anual de aproximadamente US\$300 mil, as principais atividades do Brazil Institute podem ser divididas em quatro tipos: 1) realizar painéis sobre temas de políticas doméstica e externa compostos por acadêmicos, burocratas, jornalistas e, eventualmente, políticos com interesse no tópico; 2) promover a articulação da Fapesp com universidades norte-americanas; 3 ) promover encontros entre legisladores brasileiros e institutos de pesquisa e inovação estadunidense; e 4) promover a interação entre membros dos judiciários brasileiro e estadunidense - Relatório 2014 (Brazil Institute, 2014). Seu website também abriga um portal com informações e clipping de notícias em inglês sobre o Brasil. Periodicamente, o Brazil Institute realiza jantares no Brasil para arrecadar fundos.

Nos últimos anos, entre os doadores que aportam recursos, estão a Interfarma, uma associação de empresas do setor farmacêutico estabelecidas no Brasil, além de empresas como Coca-Cola, Guerdau, Chevron, Coteminas e Amyris - Relatório 2015-2016 (Brazil Institute, 2016). Trata-se, portanto, de multinacionais com operações em ambos os países.

Em termos políticos, como parte do Wilson Center, o Brazil Institute define-se como não partidário e, no cenário ideológico estadunidense, pode ser descrito como liberal ${ }^{12}$. De forma geral, o perfil da sua atuação - publicações, eventos ou intervenções de seus quadros na grande mídia - caracteriza-se por uma maior proximidade às lógicas e agendas do campo econômico. Os debates promovidos, os problemas abordados, as soluções propostas e as políticas públicas sugeridas por esses think tanks tendem a estar em

\footnotetext{
10 Entrevista concedida em 22/3/2016.

${ }^{11}$ Entrevista concedida em 15/6/2016.

12 Isso quer dizer que, no plano externo, advoga em favor do institucionalismo liberal liderado pelos EUA, pela adoção de políticas "pró-mercado", democracia liberal e maior aproximação entre Brasília e Washington. No plano doméstico, o Wilson Center e demais think tanks liberais, ou progressives, tendem a apoiar ações do Estado em favor da redução das desigualdades sociais e da regulação da economia. Já os think tanks conservadores tendem a promover a limitação do papel do Estado na economia, a posse de armas e os valores tradicionais (Wietchikoski e Svartman, 2020). No campo político brasileiro, há forte convergência do Wilson Center com a agenda do PSDB e uma ligação com quadros desse partido ou próximos a ele, como o ex-presidente Fernando Henrique Cardoso e o ex-embaixador Rubens Barboza.
} 
sintonia com os temas de interesse do mundo dos negócios. Isso vale para a produção tanto em termos globais quanto naquilo que diz respeito à produção sobre o Brasil. É importante destacar que a produção ideacional do Brazil Institute se diferencia das demais pelo fato de boa parte dela ser de autoria de brasileiros e de ser, em grande medida, a republicação de textos veiculados em outros espaços.

Entre os think tanks que têm maior afinidade com o campo político, o mais significativo para esta pesquisa é o Council on Foreign Affairs (CFR). Trata-se de uma das mais antigas instituições, que, mais tarde, vieram a ser nomeadas como think tanks. $O$ CFR iniciou-se como uma espécie de clube de elite que, a partir de 1918, passou a reunir políticos, intelectuais e empresários para discutir temas ligados às relações internacionais dos Estados Unidos. Depois da Conferência de Versalhes, ao final da Primeira Guerra Mundial, o CFR tornou-se uma instituição permanente, promovendo também pesquisas na área e colocando-se no campo político como não partidário (bipartisan), de modo a posicionar-se oficialmente à margem das disputas entre democratas e republicanos. Desde então, capta seus recursos na sociedade civil, evitando o financiamento governamental. Em 1922, deu início à publicação da revista Foreign Affairs, um dos mais reconhecidos veículos do establishment de política externa e relações internacionais dos EUA (Abelson, 2006).

O CFR declara ter por missão ajudar seus membros, governantes, executivos, acadêmicos, jornalistas e outras lideranças a "entender melhor o mundo e as escolhas de política externa a serem feitas pelos Estados Unidos" - Relatório 2016 (CFR, 2016). Sua disposição para influência política pode ser avaliada desde cedo: no entreguerras, o CFR desempenhou papel importante, junto com seu congênere britânico, a Chatham House, no sentido de difundir ideias ligadas ao maior protagonismo externo dos Estados Unidos e em favor da aliança com o Reino Unido (Legro, 2000; Parmar, 2004) e, mais tarde, na produção do consenso em favor dos acordos de Bretton Woods (Smith, 1991).

Ainda hoje, o CFR permanece como uma membership organization, com 5 mil membros (individuais e corporativos), que têm acesso privilegiado ao seu numeroso staff. A despeito de publicar relatórios sobre temas específicos, de editar a influente Foreign Affairs e das frequentes participações de seus pesquisadores na mídia, boa parte dos eventos promovidos pelo CFR são reservados, ocasiões em que seus membros e quadros do Executivo e do Legislativo estadunidenses interagem com as demais lideranças domésticas e de outros países ${ }^{13}$. O CFR abriga 16 programas e centros que cobrem diferentes áreas (como política externa dos EUA, saúde global e segurança nacional) e regiões (como Europa, Ásia e América Latina). Em termos ideológicos, o Council on Foreign Relations é fortemente identificado com a ordem liberal capitaneada pelos Estados Unidos,

13 De acordo com o relatório de 2016, naquele ano, o CFR recebeu as visitas dos presidentes da Geórgia, Malawi e Namíbia, dos primeiros-ministros da Tunísia e Singapura, e de autoridades governamentais do Reino Unido, México, Japão, Angola, Argentina, Egito, Iraque, Itália, Letônia, Myanmar, Somália e Emirados Árabes Unidos. 
em função tanto de suas posições históricas já referidas quanto da continuada circulação de seus membros por posições proeminentes no governo dos EUA e no setor privado (Abelson, 2006). Trata-se de um dos mais longevos exemplos do fenômeno da "porta giratória" em Washington.

Por fim, entre os think tanks cujas regras de produção intelectual e de atuação estão mais próximas das práticas do campo acadêmico, nessa cartografia, tomou-se a Brookings Institution como organização mais significativa. Tendo iniciado seus trabalhos em 1916 como um instituto de pesquisas sobre governo e eficiência administrativa (Smith, 1991), atualmente a Brookings é considerada o mais influente think tank do mundo (McGann, 2016) e, como pode ser observado, um dos maiores e mais bem financiados. Possui cinco programas principais (Estudos Econômicos, Política Externa, Economia Global e Desenvolvimento, Estudos de Governança e Política Metropolitana) e vários projetos dedicados a regiões ou temas específicos. O Brasil é contemplado pelos projetos dedicados à América Latina e pelo programa Order from Chaos. Possui ainda um programa de ensino voltado à "educação executiva". Atualmente, a instituição define-se como "um local onde pesquisas rigorosas e prescrições políticas práticas, e não as agendas ideológicas, conduzem o debate". Por conta disso, afirma assegurar liberdade acadêmica a seus pesquisadores, que, isentos de pressões políticas, se dedicam a pesquisas empiricamente fundamentadas nas questões do momento - Relatório 2015 (Brookings Institution, 2015). Tanto os materiais publicados quanto os pesquisadores entrevistados ressaltam a independência das pesquisas em relação aos financiadores e mesmo à própria Brookings, que informa serem as interpretações ou conclusões dos estudos por ela publicados de responsabilidade exclusiva dos autores, à semelhança do que ocorre no campo acadêmico. Outra característica importante da Brookings é a sua grande ênfase na publicação de livros (que devem ser aprovados por um comitê editorial e por revisores no sistema "duplo cego"), para além das práticas dominantes de artigos de opinião e demais textos curtos reproduzidos em postagens em mídias sociais.

Em termos de posicionamento no espectro ideológico dos Estados Unidos, a Brookings é percebida como liberal, fortemente compromissada com o sistema internacional liderado por esse país. Como a maioria dos think tanks, a Brookings depende de doações pessoais, corporativas e governamentais para funcionar. Em 2015/2016, essas contribuições representaram $86 \%$ de suas receitas operacionais, enquanto o fundo legado por seu fundador assegurou $10 \%$ do orçamento. Entre os maiores doadores recentes, encontram-se a Fundação William e Flora Hewlett, os Emirados Árabes Unidos e o banco JP Morgan Chase - Relatório 2016 (Brookings Institution, 2016).

Uma forma de mensurar o interesse dos think tanks pelo Brasil é contabilizar o número de produções a respeito do país, ao longo do tempo, nas diferentes instituições selecionadas. Tomando isso como base, pode-se afirmar que o Brasil é um tema periférico, porém presente na agenda temática dos principais think tanks sediados em Washington. A evolução de tal presença pode ser acompanhada na Tabela 3, que computa artigos, 
livros, relatórios e textos mais concisos publicados pelos think tanks selecionados entre 2000 e 2016:

Tabela 3

Levantamento de textos sobre o Brasil por think tank e por ano

\begin{tabular}{|c|c|c|c|c|c|c|c|c|c|c|c|c|}
\hline & Brookings & CSIS & CFR & $\begin{array}{l}\text { Wilson } \\
\text { Center }\end{array}$ & CAP & AEI & $\begin{array}{l}\text { Atlantic } \\
\text { Council }\end{array}$ & Carnegie & Dialogue & CNA & INSS & $\begin{array}{c}\text { Quantidade } \\
\text { total }\end{array}$ \\
\hline 2000 & & & & & & & & & & & & 0 \\
\hline 2001 & & & & & & & & & & & & 0 \\
\hline 2002 & & 1 & 1 & 1 & & & & & & & & 3 \\
\hline 2003 & & 1 & & & & & & & & & & 1 \\
\hline 2004 & & & 1 & & & & & & & & & 1 \\
\hline 2005 & & & & & & & & & & & & 0 \\
\hline 2006 & & & & & & & & & & & & 0 \\
\hline 2007 & & & & 1 & & & & & & & & 1 \\
\hline 2008 & & & & & & & & & & & & 0 \\
\hline 2009 & & 1 & & 2 & 1 & & & & & & & 4 \\
\hline 2010 & 1 & 1 & 1 & & & & & & 4 & 1 & & 8 \\
\hline 2011 & 1 & & 1 & & & & & & & & 1 & 3 \\
\hline 2012 & 1 & 3 & & 1 & & & & & 3 & & 1 & 9 \\
\hline 2013 & & 1 & & 2 & & & & & & 1 & & 4 \\
\hline 2014 & 2 & 4 & 2 & 1 & 1 & & & 3 & 9 & 1 & 1 & 24 \\
\hline 2015 & 2 & 3 & 2 & 2 & & 2 & 8 & 3 & 5 & & & 27 \\
\hline 2016 & 13 & 2 & 9 & 6 & 1 & 8 & & 4 & 14 & & & 57 \\
\hline Total & 20 & 17 & 17 & 16 & 3 & 10 & 8 & 10 & 35 & 3 & 3 & 142 \\
\hline
\end{tabular}

Fonte: Elaboração própria a partir de levantamento feito pelo autor.

A incidência de textos a respeito do Brasil é desigualmente distribuída tanto por instituição quanto cronologicamente. Tomando como critério o número de publicações, pode-se dizer que The Dialogue e Brookings, seguidos do CSIS, CFR e Wilson Center, são os think tanks que conferiram mais atenção ao Brasil. Pode-se constatar também que, de 2000 a 2008, a produção a respeito do país foi pequena e episódica (apenas seis artigos), indicando que este estava "fora do radar de Washington", como diz a gíria local. Acrescenta-se a isso o fato de o programa destinado ao Brasil do Wilson Center ser ainda incipiente, uma vez que fora criado em 2006.

De 2009 a 2013, observa-se um sensível aumento de publicações a respeito do Brasil (28 textos), havendo, inclusive, material de maior envergadura, como o relatório de uma força tarefa do CFR, em 2011. Esse aumento expressivo pode ser entendido como um 
esforço para avaliar o que foi e o que significaria para os EUA o maior protagonismo externo do Brasil, que, no período, se tornou mais visível em Washington por conta de sua atuação no G-20, Brics e Ibas, da criação da União das Nações Sul-Americanas (Unasul), da atuação, junto com a Turquia, na negociação de um acordo nuclear com o Irã e da apresentação da experiência brasileira de redução da pobreza como modelo para o Sul global em meio às crises financeira e econômica que se alastravam em 2009. É importante destacar que, até esse período, as publicações sobre o Brasil abordavam majoritariamente questões ligadas a educação, desigualdade social ou meio ambiente. Desde então, o Brasil, sua atuação internacional e sua política doméstica tornaram-se objeto de interesse de um maior número de instituições. No breve intervalo de 2014 a 2016, 108 textos foram publicados pelos think tanks de Washington. Esse número expressivo, contudo, reflete não apenas a maior visibilidade que o país adquiriu nos debates a respeito dos emergentes, mas também o progressivo desgaste dessa imagem, por conta dos escândalos de corrupção, do impeachment de Dilma Rousseff e da crise econômica que abateu o país.

É possível afirmar que os think tanks que mais publicaram a respeito do Brasil estão mais próximos do campo econômico, onde se destaca também a prevalência dos doadores privados. Think tanks mais próximos do campo acadêmico e do campo político publicaram quantidade semelhante de textos, porém abaixo daqueles mais próximos ao campo econômico. Tendo em mãos tal descrição da paisagem dos think tanks estadunidenses e essa breve quantificação de seu interesse pelo Brasil, é possível agora abordar a produção ideacional deles sobre a atuação externa do país.

\section{A narrativa dos valores compartilhados}

Ao longo do período estudado, a produção ideacional dos think tanks dos EUA a respeito do Brasil enfatizou traços comuns e convergências entre os dois países. As abordagens do maior ativismo externo do Brasil na primeira década do século XXI estiveram associadas a descrições, em geral positivas, dos ativos (assets) conquistados pelo país nos últimos anos. Estes seriam: o controle da inflação, o que revertia uma visão arraigada, desde os anos 1980, de um país economicamente instável; a consolidação da democracia, com a eleição de governos "à esquerda do centro" que, não obstante, mantinham as "regras do jogo" político e o "cumprimento dos contratos" econômicos; um período relativamente longo de crescimento econômico em ambiente de economia de mercado; e a adoção de programas de redução da pobreza bem-sucedidos.

O exemplo mais importante dessa narrativa positiva que enfatiza aspectos em comum e sugere maior aproximação e coordenação entre os Estados Unidos e o Brasil é o extenso relatório publicado pelo CFR em 2011, intitulado Global Brazil and U.S.-Brazil relations (Bodman, 2011). O documento, de 110 páginas, resultado do trabalho de uma força-tarefa, afirma que os Estados Unidos e o Brasil são ambos "multiethnic, young democracies that uphold common values with respect to free markets, rule of law, 
individual rights, religious freedom, and diversity and equality" (p. 4). O relatório enfatiza não apenas o papel do Brasil no plano regional, mas sua relevância global em questões ligadas a economia, meio ambiente, energia e diplomacia, sendo apresentado como um dos poucos países destinados a modelar o século XXI ( $p . x$ ). Por conta disso, em várias passagens, o documento recomenda que os Estados Unidos adaptem sua política a esse "novo" ator mais "assertivo e independente", de modo a incrementar as relações bilaterais e, em especial, a assegurar seus próprios interesses numa ordem internacional mais multipolar e menos previsível, através da interação direta entre as lideranças e os corpos diplomáticos, o que, ainda segundo o documento, configuraria uma "relação madura" entre os dois países. Em função disso, o relatório recomendou que, entre outras iniciativas, o governo Barack Obama apoiasse o pleito brasileiro por um assento permanente no Conselho de Segurança das Nações Unidas (p. 47 e 46).

Essa visão de que a ascensão do Brasil, por conta das convergências de modelo econômico, valores e sistema político, seria uma oportunidade para os Estados Unidos e para um redesenho mais confortável (para os EUA) do sistema internacional tornou-se bastante difundida no espaço dos think tanks de Washington. Alimentou-se a expectativa de que o Brasil atuaria de maneira "construtiva" com os Estados Unidos. Essa percepção foi sintetizada por um dos entrevistados nos seguintes termos:

the United States, its security and its interests are best secured when there is an international liberal order that functions, in which constitutional democracies that respect human and political rights to some degree most of the time collaborate and cooperate under the rule of law. (...) Brazil is a lawabiding international actor and it operates through the United Nations and through the WTO. It is certainly a participatory and it could be a greater contributing country in the future in those forums and in that system. And to the extent that Brazil operates within that system, its expression and its interests are very likely to align more or less in the greater with the United States ${ }^{14}$.

Ainda que com ressalvas, essa visão difundiu-se também entre os círculos mais conservadores. Os textos publicados pelo American Enterprise Institute, sempre críticos às políticas econômicas e sociais dos governos brasileiros "populistas", frequentemente descreveram o Brasil como um mercado importante para os EUA; e, mesmo no cenário adverso dos escândalos de corrupção, um de seus quadros mais prolixos, o ex-embaixador Roger Noriega, apresentava o Brasil, em 2015, como um país que, diferente da Argentina e da Venezuela, possuía um judiciário "respeitado por seu rigor e independência" (Noriega e Trigos, 2015, p. 4).

\footnotetext{
${ }^{14}$ Entrevista com Ralph Espach, do CNA, em 28/12/2015.
} 
Esse movimento de descrever o Brasil como similar aos Estados Unidos e distinto, ou mesmo oposto, de outros países como Venezuela e também, conforme será demonstrado adiante, China e Rússia, revela um esforço continuado de refutação dos Brics como grupo. Em geral, salientaram-se a assimetria da economia chinesa em relação aos demais ${ }^{15}$, as violações de soberania praticadas pela Rússia e a limitada capacidade de coordenação do grupo ${ }^{16}$ como argumentos contrários à participação brasileira e indiana no grupo. Em oposição, as narrativas enfatizaram a democracia liberal e até o passado escravista como elementos em comum entre Brasília e Washington (Brimmer, 2014, p. 149).

Em 2016, a Brookings Institution publicou o que talvez seja o mais extensivo esforço de um think tank baseado em Washington em decifrar a atuação internacional do Brasil e avaliar suas consequências para os EUA. O livro de David Mares e Harold Trinkunas, Aspirational power: Brazil on the long road to global influence, aborda a conduta do Brasil em questões de segurança internacional, negociações econômicas, ambientais e de regulação da internet. Nesta seção, cabe apenas enfatizar o sentido que os autores atribuem à eventual incorporação do Brasil ao grupo das grandes potências:

Brazil's incorporation benefits not only Brazil but also provides needed legitimacy to liberal global governance. Brazil's failure to emerge makes it appear that the liberal global order is stacked against the South and complicates the evolution of the global order (Mares e Trinkunas, 2016, p. 181).

A narrativa dos valores compartilhados consiste num esforço para enfatizar os pontos de convergência entre os dois países e definir um papel "construtivo" do Brasil para a legitimação, gestão e preservação da ordem internacional liderada pelos Estados Unidos. Num cenário regional de atritos com os países da Alba (Alternativa Bolivariana para as Américas), liderados pela Venezuela, e de instabilidade econômica da Argentina, o Brasil foi descrito como um ator comprometido com a democracia, a estabilidade e a economia de mercado. No plano global, com a ascensão da China e a retomada da Rússia (normalmente descritas como potências autoritárias e desafiadoras da ordem internacional e da liderança dos EUA), o Brasil foi descrito, apesar do incômodo com os Brics, como ator comprometido com a democracia, os direitos humanos e a manutenção, moderadamente reformada, da ordem internacional.

É nesse sentido que se deve compreender a recepção majoritariamente positiva dos programas de aquisição de sistemas de armas modernos das forças armadas brasileiras. Havia a expectativa de que as forças armadas brasileiras, contando com maiores capacidades, cooperassem com os Estados Unidos em questões de segurança

\footnotetext{
15 Entrevista com Peter Hakim, do The Dialogue, em 20/1/2016.

16 Entrevista com Esther Brimmer, do CFR, em 26/4/2016, e com Ted Piccone, da Brookings, em 5/4/2016.
} 
marítima e missões de paz $^{17}$, ou ainda, contribuíssem para a estabilidade em regiões nas quais a presença dos EUA tivesse maior custo político (INSS, 2009). Havia ainda o interesse econômico da indústria de defesa, importante financiadora de vários think tanks, em ser fornecedora dos projetos ${ }^{18}$.

Salienta-se que os programas poderiam ter sido enquadrados como uma ameaça, especialmente a construção do submarino de propulsão nuclear, ainda mais considerando a continuidade das restrições de acesso às tecnologias nuclear e aeroespacial em vigor. Todavia, a reduzida percentagem do PIB brasileiro dedicada ao orçamento de defesa e os posteriores atrasos e problemas de financiamento dos projetos contribuíram para que não houvesse um discurso securitizante a respeito dos investimentos brasileiros em defesa nos think tanks dos EUA ${ }^{19}$.

Finalmente, é importante destacar que uma parte dessa narrativa positiva foi intencionalmente compelida pela diplomacia brasileira. Em 2014, a Agência Brasileira de Promoção de Exportações e Investimentos (Apex) aportou recursos ao CSIS, um dos mais influentes think tanks com forte presença na área de defesa e segurança internacional, que, por sua vez, criou a Brazil Initiative no âmbito do Americas Program (Belli e Nasser, 2014). A iniciativa promoveu eventos e publicou informes e artigos sobre o Brasil, com destaque para a cooperação em defesa com os Estados Unidos.

\section{Dissenso, desconfiança, decepção}

A narrativa favorável ao Brasil não circulou, contudo, sem contrapontos importantes. Dois temas demarcaram o dissenso da produção ideacional dos think tanks dos Estados Unidos sobre a atuação internacional brasileira: a aplicação do princípio da soberania nacional em oposição à legitimidade de intervenções externas e à adesão do Brasil ao grupo dos Brics.

Durante o período abordado nesta pesquisa, Brasil e Estados Unidos estiveram em campos diferentes, quando não opostos, numa série de crises que puseram em evidência a tensão entre o princípio westfaliano de soberania estatal e o da segurança humana. Assim, em 2011, nas crises da Líbia e do início da guerra civil na Síria, Washington interveio militarmente enquanto Brasília sustentava que o emprego da força não traria segurança às populações afetadas nem estabilidade à região. O caso da Líbia é particularmente relevante para esta pesquisa porque, embora a intervenção tenha sido sob mandato das Nações Unidas (Resolução 1973 do Conselho de Segurança), a decisão esteve longe de ser unânime. Naquela circunstância, Brasil, Índia e Alemanha eram membros rotativos do Conselho e abstiveram-se de aprovar a Resolução, assim como China e Rússia.

\footnotetext{
17 Entrevistas com Ted Piccone, da Brookings, em 5/4/2016, e com Margaret Heyes, do CFR, em 4/4/2016.

18 Entrevista com Ralph Espach, do CNA, em 28/12/2015.

19 Entrevista com Toghzan Kassenova, da Carnegie, em 6/4/2016.
} 
A mobilização dos discursos da não indiferença e da responsabilidade ao proteger, por parte do Brasil, num cenário em que o país ainda estava em ascensão econômica e bastante proativo internacionalmente, repercutiu quase tanto quanto a votação e o quase alinhamento integral dos países dos Brics $^{20}$. Embora a autodeterminação dos povos e a não intervenção sejam parte dos "princípios e valores inerentes à política exterior" brasileira (Cervo, 1994), o tema foi encarado como algo novo e objeto de consideração por parte dos think tanks estadunidenses.

O já referido livro de Mares e Trinkunas, publicado pela Brookings, procurou tratar o tema como parte de um padrão de ação internacional no qual o Brasil, embora fosse um apoiador da ordem internacional liderada pelos EUA (e dos valores que lhe são inerentes), estaria procurando revisá-la e reformá-la de modo a criar constrangimentos ao comportamento unilateral dos Estados Unidos. Isso, por si, representaria um "desafio" às preferências das potências incumbentes (Mares e Trinkunas, 2016, p. 18).

Em síntese, afirmam:

Brazil uphold the four principles of the international order: sovereignty, sovereign equality, international peace, and market economy. (...) Brazil has (...) never been a revolutionary power and it has never sought to overthrow the existing order as Napoleonic France, Nazi Germany or Soviet Union once did. But it does seek more than reform or simply take a part in existing institutions with some adjustments to reflect its rising power. It seeks a revision in the relative importance of the prevailing order by ranking the norm of sovereign equality above all others (p. 168).

No argumento, está implícito que, embora o Brasil não seja uma ameaça (inclusive em função das suas limitadas capacidades militares), a sobrevalorização de um dos princípios que regem a ordem internacional seria uma manobra para balancear o poder militar estadunidense com as regras do direito internacional. Outro quadro da Brookings, Piccone, procurou dar sentido à divergência brasileira em relação aos Estados Unidos, argumentando que Brasil e Índia, por buscarem um assento permanente no Conselho de Segurança das Nações Unidas, evitariam criticar abertamente regimes não democráticos e, com isso, reforçariam seus laços de solidariedade Sul-Sul (Piccone, 2016, p. 228). Visões ainda menos matizadas sustentaram que o Brasil tomava o conceito de soberania como algo absoluto e abstrato, o que poderia justificar até genocídios no "mundo real", ou simplesmente que o país se pautava por uma política exterior dos anos 1970, dos Não Alinhados, e que não queria usar os "botões do poder" quando se contrapunha ao emprego de força militar ${ }^{21}$.

\footnotetext{
${ }^{20}$ A África do Sul também era membro rotativo do Conselho de Segurança naquele momento, contudo votou a favor da Resolução 1973.

${ }^{21}$ Entrevista com Peter Hakim, do The Dialogue, em 20/1/2016, e com Peter Schechter, do Atlantic Council, em 13/1/2016.
} 
Por mais que o intervencionismo dos Estados Unidos estivesse sob crítica, inclusive internamente, o desconforto com a posição brasileira divergente foi claro. Entretanto, ele teria sido maior se fosse causado por uma eventual aproximação ou identificação com a China e a Rússia no âmbito dos Brics. Por ocasião da Cúpula dos Brics de 2014, em Fortaleza, Brasil, o Center for American Progress (think tank bastante próximo ao partido Democrata) publicou um relatório que recomendava que os Estados Unidos não vissem o grupo dos Brics como uma ameaça, mas que tratassem de se aproximar de cada um desses países individualmente, de modo a evitar que isso acontecesse. O relatório enfatizava, ainda, que, embora o sistema de governança global apresentasse fissuras, nem os Brics nem qualquer outro grupo de países ofereciam uma alternativa a esse sistema (ElginCossart, 2014). Num contexto de atritos comerciais e geopolíticos com a China e de recrudescimento de tensões com a Rússia (especialmente depois das crises na Ucrânia e na Síria), a produção ideacional dos think tanks analisados sobre os Brics acentuou a denotação negativa. De forma geral, procuravam enfatizar as assimetrias e a pouca coordenação entre os membros do grupo, e tentavam dissociar Brasil e Índia de Rússia e China. Nesse sentido, Erik Fransworth, do Council on Americas, definiu os Brics como "a political entity [with] an independent voice apart from the USA and apart from the western structures of global issues", o que seria bastante "inconveniente" aos EUA 22 . O tema tornou-se mais sensível depois da recusa brasileira em apoiar as sanções à Rússia propostas por Washington na ONU, por conta da anexação da Crimeia. Ensejando o questionamento a respeito da identidade do Brasil, mais especificamente em relação à identificação do Brasil com as democracias ou com os Brics. Conforme Trinkunas, "one of the reasons why I think that more recently Brazil and the U.S have had so many issues with Brazil's emphasizing the Brics part of its identity"23. O esforço discursivo de deslegitimar e dissociar os membros dos Brics por parte dos think tanks pode ser sintetizado na seguinte passagem do livro de Piccone sobre as "democracias emergentes":

The Brics framework, well endowed by China deep pockets, appears to be overshadowing the group, intentionally or not. An invigorated and/or expanded IBSA, to include states like Indonesia, Mexico, and South Korea, could forge an alternative and complementary path toward international support for democracy (2016, p. 228 e 229).

O apoio ao Ibas em oposição aos Brics não é desprovido de interesse e tampouco esconde a manutenção da hierarquia do sistema que as análises dos think tanks normalmente ensejam:

If paired with more coercive approach led by established democracies, such a group could serve a salutary 'good cop, bad cop' function, like the role

\footnotetext{
22 Entrevista com Eric Fransworth, do Council on Americas, em 23/2/2016.

23 Entrevista concedida em 11/2/2016.
} 
Indonesia and Asean played in Myanmar vis-à-vis the sanctions regime of the West (Piccone, 2016, p. 229).

Tais produções ideacionais reforçam o argumento de que o grupo dos Brics não é um ator coletivo legítimo no espaço dos think tanks dos Estados Unidos (Teixeira, 2011). Além disso, revelam que o "engajamento" e a "relação madura" entre o Brasil e os Estados Unidos fazem sentido, para os atores que operam no "mercado de ideias" de Washington, na medida em que o Brasil divida os custos de manutenção da ordem internacional e da posição que os EUA ocupam nela. Havia pouco espaço para acomodar visões diferentes e formas de gerenciar crises menos inclinadas ao uso da força naquele ambiente, mesmo num governo disposto a reduzir a presença militar global dos Estados Unidos.

Ao dissenso, a produção discursiva dos think tanks a respeito do Brasil passou a manifestar certo grau de desconfiança quanto ao compromisso brasileiro com a ordem internacional e quanto à sua capacidade de "entregar bens comuns" em favor dela. Um campo no qual a desconfiança se mostrou mais evidente foi o da energia nuclear, tema que historicamente tem gerado atritos entre Brasília e Washington. O Carnegie Endowement for International Peace publicou um livro em 2014 e, desde então, vários textos menores de uma de suas pesquisadoras a respeito do programa nuclear brasileiro. Essa obra de 2014, de Kassenova, revela pesquisa consistente e visão nuançada dos objetivos, motivações e desenvolvimentos da política e do programa nuclear brasileiros. A autora não endossa visões alarmistas sobre outro uso que não o pacífico para a energia nuclear no Brasil, contudo, ao abordar as críticas feitas pela diplomacia brasileira ao regime internacional que regula a pesquisa e o emprego da energia nuclear, conclui prevendo que:

countries like Brazil should not be expected to take on any further nonproliferation obligations. In that respect, Brazil's distaste for the IAEA Additional Protocol and concerns about proposals to change the approach to international safeguards (that is, the debate on the state-level approach) will likely persist (Kassenova, 2014, p. 88).

Kassenova ressalta que o Brasil vive uma situação paradoxal de, ao mesmo tempo, criticar o caráter injusto da ordem nuclear e procurar inserir-se nela, o que elevaria os custos de manutenção da ordem para as potências estabelecidas:

Brazil's case is a perfect example of the type of tensions that are intensifying within the global nuclear order: those between nuclear-armed and nonnuclear-weapon states, between disarmament and nonproliferation, and between nonproliferation and peaceful nuclear energy. These tensions are not new, but they are becoming harder to ignore. In the past, established nuclear powers could more easily dismiss complaints from non-nuclear states about the lopsided order, but the non-nuclear states have gradually become more 
active and vocal, pushing the order to evolve and making outright dismissal more difficult (Kassenova, 2014, p. 88).

Com esse pano de fundo, é possível compreender visões como a de Peter Hakim, do The Dialogue, o qual sustenta que o governo estadunidense seria cauteloso ao fornecer tecnologia nuclear ao Brasil porque não confia no uso que o país faria dela. Para Hakim, a cada avanço tecnológico, o Brasil poderia mudar o "cálculo" com relação ao seu emprego, afetando, assim, a política de não proliferação de armas nucleares liderada pelos EUA. Questionado sobre a restrição constitucional brasileira do uso de armas nucleares e sobre o regime de mútuo controle com a Argentina, o entrevistado argumentou que constituições latino-americanas podem ser alteradas e que a Argentina não é exatamente confiável ${ }^{24}$. A desconfiança nesse campo traduz-se também na "preocupação" (concern) de alguns quadros de think tanks quanto à viabilidade econômica do programa de construção do submarino de propulsão nuclear brasileiro ${ }^{25}$.

Os impactos das crises econômica e política ao longo de 2015 e 2016 e o consequente retraimento brasileiro da cena global ensejaram várias publicações dos think tanks tentando descrever os contornos (e potenciais consequências) desse turbulento processo. De forma geral, questionava-se a respeito da capacidade do Brasil de "manter seu engajamento internacional" e de "cumprir suas obrigações", ou se ainda se tratava de um país em ascensão. Parte dessa produção engendrou uma narrativa de decepção com a atuação internacional do Brasil, enfatizando, por um lado, o que entendiam ser o apoio do Brasil aos regimes não democráticos de China, Rússia e Venezuela e, por outro lado, as próprias fragilidades do sistema político brasileiro.

Mares e Trinkunas (2016, p. 80) fornecem um claro exemplo da decepção dos think tanks estadunidenses quanto às possibilidades de Brasil e Estados Unidos convergirem na "governança da ordem global", particularmente em assuntos securitários:

So strong was Rousseff's interest in maintaining good relations with the BRICS that she overlooked fairly egregious international behavior by her partners. In particular Russia annexation of Crimea and intervention in Ukraine, both of which were deeply contrary to Brazil's expressed preference for the inviolability of international borders, were resolutely ignored by Brazilian diplomacy.

Essa visão foi secundada por entrevistados mais próximos do campo político, como Esther Brimmer (secretária assistente de Estado para Assuntos de Organizações Internacionais de 2009 a 2013), que salientou que:

\footnotetext{
24 Entrevista com Peter Hakim, concedida em 20/1/2016,

25 Entrevistas com Margareth Heyes, do CFR, e Luis Bitencourt, do INSS, em 4/4/2016 e 22/3/2016, respectivamente.
} 
(...) there is a frustration in the sense of inconsistency.(...) Because the invasion of Ukraine - first Crimea and then extended to the eastern provinces - was clearly a violation of international law, and it seemed to me that Brazil should have been much more outspoken about it for some reasons ${ }^{26}$.

E também por entrevistados mais próximos do campo acadêmico, como Piccone, o qual salientou que:

[Brazil] didn't oppose Russia's invasion of Crimea. (...) That was a big surprise to a lot of us. Brazil has been the champion of international law and sovereignty, and this was such an obvious violation. Now, that looked to me like a decision to privilege its relations with the BRICS - with Russia - over its own principles ${ }^{27}$.

Com relação à fragilidade doméstica para dar sustentação à performance internacional do Brasil, Margareth Hayes, do CFR, declarou que "there is a great disappointment with the turn of events, the corruption scandal. (...) I think there is a recognition that the government is not as strong and sour as might have been, as maybe Lula sold". Visão não muito diferente de Kassenova, para quem o Brasil se tornara um país introvertido, sobrecarregado pelos problemas domésticos, mostrando-se, então, como uma promessa não cumprida (unfulfilled promise) ${ }^{28}$. Para Peter Hakim, essa fragilidade doméstica teria minado a credibilidade do Brasil e o interesse dos Estados Unidos em manter maior "engajamento", uma vez que:

Brazil's deep and complex domestic troubles are reason enough for the US to exercise caution in dealing with the country. Although Rousseff's impeachment has followed constitutional norms, many in Brazil and worldwide doubt the legitimacy of the proceedings. There are valid concerns about the seriousness of the charges and the fairness of a verdict emerging from the many scandal-tainted, unscrupulous politicians sitting in judgment of her. Compared to them, she seems honest and clean (Hakim, 2016) ${ }^{29}$.

Por fim, cabe recuperar aqui o argumento de Mares e Trinkunas, para quem a emergência internacional do Brasil observada no início do presente século esteve fortemente amparada no seu soft power ou na "atratividade de seu modelo". Para os autores,

Brazil's efforts to use soft power to intervene in the security and economic domains in the 2000s (...) came to naught. And when international conditions

\footnotetext{
${ }^{26}$ Entrevista com Esther Brimmer, do CFR e Atlantic Council, em 26/4/2016.

27 Entrevista com Ted Piccone, da Brookings, em 5/4/2016.

28 Entrevista com Toghzan Kassenova, da Carnegie, em 5/4/2016.

${ }^{29}$ Disponível em: <https://www.thedialogue.org/analysis/defrosting-us-brazilian-relations/>. Acesso em: 3 nov. 2021.
} 
become less favorable for Brazil's exercise of soft power, the weakness of its domestic institutions, which have been historically prone to economic and political crisis, become more salient and further undercut the hard and soft power needed to power its emergence (Mares e Trinkunas, 2016, p. 19).

\section{Considerações finais}

A pesquisa aqui relatada permitiu mapear quais think tanks estadunidenses se engajaram na tarefa de produzir narrativas sobre a atuação internacional do Brasil para a audiência de decisores políticos, legisladores e burocratas e da opinião pública daquele país. Ao situar o contexto mais amplo do chamado "mercado de ideias", que compõe o espaço social dos think tanks de Washington, puderam-se constatar o volume da produção dessas organizações mais próximas do campo econômico, o perfil das recomendações dos think tanks mais próximos do campo político e o compromisso com a ordem internacional daqueles mais identificados com o campo acadêmico.

É importante salientar que segmentos da sociedade e do Estado brasileiros procuraram influir na produção ideacional dos think tanks aqui estudados. Nesse sentido, observou-se que o Brazil Institute do Wilson Center gravitava próximo do mundo corporativo de São Paulo e de quadros ligados ao PSDB, o que talvez explique a opção da embaixada brasileira pelo CSIS para sediar o breve programa sobre o Brasil, o qual, por sua vez, orbitou mais em torno da própria embaixada que dos atores políticos ou privados. Na maior parte do recorte temporal desta pesquisa, o Brasil foi governado por coalizões lideradas pelo Partido dos Trabalhadores; entretanto, não se identificou presença significativa de seus quadros ou lideranças nos think tanks investigados.

É possível afirmar que, no período desta pesquisa, o Brasil esteve na "tela do radar" dos think tanks de Washington. Houve produção significativa em várias dessas organizações cujas ideias são influentes nos Estados Unidos e internacionalmente. Aferir com precisão quais políticas contaram com a contribuição dos think tanks em sua formulação e implantação e em que medida é sempre algo difícil (Abelson, 2006); contudo, é possível alinhar algumas decisões do governo estadunidense com a produção ideacional analisada como forma indireta de avaliar o impacto da sua produção ideacional.

Essa produção procurou decifrar o que significaria, para os Estados Unidos, o Brasil como um emergente. Tendo em vista a Venezuela, na região, e Rússia e China, globalmente, os think tanks investigados articularam e disseminaram uma narrativa que descrevia o Brasil como um país que partilhava valores e interesses com os Estados Unidos, o que justificaria o "engajamento". Tal prescrição coincide com o "diálogo estratégico" bilateral estabelecido ainda em 2005, com o acordo militar de 2010 e com a relativa passividade de Washington diante do empenho brasileiro na criação da Unasul, em 2008, e da Celac (Comunidade de Estados Latino-Americanos e Caribenhos), em 2010. O fato de os EUA não terem bloqueado os programas de modernização dos sistemas de armas 
brasileiros - para além do que já vigorava na política de não proliferação - também coincide com a narrativa positiva dos think tanks. Afinal, a possibilidade de aqueles programas resultarem em contratos para a indústria de defesa dos EUA (especialmente para a Boeing) e a expectativa de que, possuindo maior capacidade militar, o Brasil fosse mais proativo na estabilização de outros países, como vinha fazendo no Haiti, convergiam com as estratégias de acomodação de atores "responsáveis" do final do governo Bush e de "divisão do fardo" do governo Obama.

A narrativa dos think tanks que enfatizou o dissenso, a desconfiança e a decepção quanto à ação internacional do Brasil seguiu tanto as divergências políticas entre os dois países em temas sensíveis, como o acordo nuclear com o Irã e as crises na Síria e Ucrânia, quanto as crises política e econômica que assolaram o Brasil. Um indicador nesse sentido é o fato de o governo estadunidense não apoiar abertamente o pleito brasileiro de um assento permanente no Conselho de Segurança das Nações Unidas, ao contrário do que fizera com a Índia, em 2010. Da mesma forma, a espionagem estadunidense das comunicações dos mandatários do Brasil, da Índia e da Alemanha, reveladas em 2013, sugere que a desconfiança quanto ao comportamento do Brasil era partilhada também pelo setor de inteligência dos Estados Unidos.

A produção ideacional dos think tanks destina-se a, com base na legitimidade da expertise, prover atores políticos de elementos para tomar "decisões informadas" e modelar o debate público. No caso em tela, essa produção acompanhou o ciclo de expansão e retração da atuação internacional do Brasil, ainda que o país continuasse sendo objeto de interesse dos think tanks estadunidenses por outros motivos. Os desdobramentos posteriores da produção ideacional a respeito do Brasil, assim como suas articulações com as mudanças nos ambientes políticos de Washington e de Brasília, consistem numa agenda de pesquisas relevante para compreender as relações bilaterais e a atuação internacional dos dois países.

\section{Referências bibliográficas}

AbELSON, D. A capitol idea: think tanks and US foreign policy. Toronto: McGill-Queen's University Press, 2006.

BeLLI, B.; NASSER, F. "Ideias de política e política de ideias: a paisagem dos think tanks nos EUA e as estratégias de inserção do Brasil no debate global". Política Externa, vol. 23, no 2, p. 153-172, out.dez. 2014.

Bodman, S. W., et al. Global Brazil and U.S.-Brazil relations. New York: Council on Foreign Relations, 2011.

BRAZIL INSTITUTE. Biannual report 2014. Washington, DC: Woodrow Wilson International Center for Scholars, 2014. Scholars, 2016.

Biannual report 2015-2016. Washington, DC: Woodrow Wilson International Center for 
OS THINK TANKS DOS ESTADOS UNIDOS E A PRODUÇÃO DE IDEIAS SOBRE O BRASIL COMO PAÍS EMERGENTE, $2000-2016$

BRIMMER, E. "Is Brazil a 'responsible stakeholder' or a naysayer?". The Washington Quarterly, vol. 37, no 3, p. 135-151, 2014.

BRoOKINGS INSTITUTION. 2015 annual report. Washington, DC: Brookings Institution, 2015. 2016 annual report. Washington, DC: Brookings, 2016.

Cervo, A. (org.). O desafio internacional: a política exterior do Brasil de 1930 a nossos dias. Brasília: Editora da UnB, 1994.

CFR - Council on Foreign Relations. Annual report 2016. Washington, DC: CFR, 2016.

Domhoff, W. Who rules America? New Jersey: Prentice Hall, 1967.

ELgin-Cossart, M. What to watch at the Brics Summit in Brazil. Washington, DC: Center for American Progress, 2014.

FRANÇA, A. "As representações da política externa brasileira por think tanks estadunidenses (20012014)". Monografia em Relações Internacionais. UFRGS, 2015.

HAKIM, P. Defrosting US-Brazilian relations. Washington, DC: The Dialogue, 2016. Disponível em: <https://www.thedialogue.org/analysis/defrosting-us-brazilian-relations/>. Acesso em: 3 nov. 2021.

HURRELL, A. "Hegemony, liberalism and global order: what space for would-be great powers?". International Affairs, vol. 82, no 1, p. 119, 2006. Disponível em: <https://doi.org/10.1111/j.14682346.2006.00512.x>. Acesso em: out. 2021.

IKENBERRY, G. J. Liberal Leviathan: the origin, crisis and transformation of the American world order. Princeton: Princeton University Press, 2011.

INSS - Institute for National Strategic Studies. America's security role in a changing world. Washington, DC: NDU Press, 2009.

KAHLER, M. "Rising powers and global governance: negotiating change in a resilient status quo". International Affairs, vol. 89, p. 711-729, 2013. Disponível em: <https://doi.org/10.1111/14682346.12041>. Acesso em: out. 2021.

KASSENOVA, T. Brazil's nuclear kaleidoscope: an evolving identity. Washington, DC: Carnegie Endowment for International Peace, 2014.

Turbulent times for Brazil's nuclear projects. Washington, DC: Carnegie Endowment for International Peace, 2015.

LEGRO, J. "Whence American Internationalism". International Organization, vol. 54, no 2, p. 253-289, 2000.

. "The plasticity of identity under anarchy". European Journal of International Relations, vol. $15, n^{\circ} 1$, p. 37-65, 2009.

MARES, D.; TRInkUnAS, H. Aspirational power: Brazil on the long road to global influence. Washington, DC: Brookings Institution Press, 2016.

McGanN, J. Global go to think tank index report. Philadelphia: University of Pennsylvania, 2016. McGanN, J.; SABATINI, R. Global think tanks: policy network and governance. London and New York: Routledge, 2011. 
McGann, J.; WeAver, K. Think tanks and civil societies: catalysts for ideas and action. New Brunswick: Transaction Publishers, 2000.

MeARSheimer, J. The tragedy of great power politics. New York: Norton, 2014.

Medvetz, T. Think tanks in America. Chicago: Chicago University Press, 2012.

NoriegA, R.; Trigos, F. Can Brazil overcome economic malaise and scandal? Washington, DC: AEI, 2015.

PARMAR, I. Think tanks and power in foreign policy: a comparative study of the role and influence of the Council on Foreign Relations and the Royal Institute of International Affairs, 1939-1945. New York: Palgrave, 2004.

Pecequilo, C. Os Estados Unidos e o século XXI. Rio de Janeiro: Elsevier, 2012.

PICCONE, T. Five rising democracies: and the fate of the international liberal order. Washington, DC: Brookings Institution Press, 2016.

Posen, B. Restraint: a new foundation for US grand strategy. Ithaca: Cornell University Press, 2014.

RICCI, D. The transformation of American politics: the new Washington and the rise of think tanks. New Haven: Yale University Press, 1994.

Saraiva, M. G. "Balanço da política externa de Dilma Rousseff: perspectivas futuras?". Relações Internacionais, Lisboa, no 44, p. 25-35, dez. 2014.

SMITH, J. The idea brokers: think tanks and the rise of the new policy elite. New York: Free Press, 1991.

Stone, D. Capturing the political imagination: think tanks and political process. London: Frank Cass, 1996.

Stone, D.; Denham, A. (eds.). Think tank traditions: policy research and the politics of ideas.

Manchester: Manchester University Press, 2004.

Svartman, E.; Silva, A. R. "Castigo sem crime? Raízes domésticas e implicações internacionais da crise brasileira". Conjuntura Austral, vol. 7, no 35, p. 4-14, maio 2016.

TEIXEIRA, T. "Os Brics na visão dos principais think tanks norte-americanos". Carta Internacional, vol. 6, no 2, p. 132-145, 2011.

Vezirgiannidou, S. "The United States and rising powers in a post-hegemonic global order". International Affairs, vol. 89, no 3, p. 635-651, 2013.

Vigevani, T.; Cepaluni, G. "A política externa de Lula da Silva: a estratégia da autonomia pela diversificação". Contexto Internacional, Rio de Janeiro, vol. 29, no 2, p. 273-335, dez. 2007.

VILLA, R. D.; VIANA, M. "Security issues during Lula's administration: from the reactive to the assertive approach". Revista Brasileira de Política Internacional, Brasília, vol. 53, p. 91-114, dez. 2010.

Wietchikoski, L.; SVARTMAN, E. "Decifrando o 'Trump tropical': análise das percepções dos think tanks dos Estados Unidos sobre a eleição e o governo Bolsonaro". Conjuntura Austral, Porto Alegre, vol. 11, no 56, p. 7-19, nov. 2020.

Wilson Center. Think Brazil, no 1, Wilson Center: Washington, DC, 2002. 
ZAHRAN, G. Tradição liberal e política externa nos Estados Unidos: um diálogo com interpretações realistas e idealistas. Rio de Janeiro: Apicuri, 2012.

\begin{abstract}
The United States think tanks and the production of ideas about Brazil as an emerging country, 2000-2016

The article analyzes the representations produced by American think tanks regarding Brazil between 2000 and 2016, a period of greater Brazilian external prominence and whose international projection represented an epistemic challenge for the Washington establishment. For that, the institutional panorama in which this ideational production was articulated and disseminated in the United States was depicted, and the methodology of content analysis was employed to investigate these publications and the interviews carried out with actors who operate in this environment. It is argued that this production fed a narrative of shared values in which Brazil would act in a convergent manner with the US in sharing the costs of maintaining order in regions such as South America and West Africa. However, the dissent regarding the principle of sovereignty and the role of the BRICS and the retraction of foreign policy, accentuated by the Brazilian domestic crisis, also engendered a narrative that emphasizes distrust of Brazilian capabilities and disappointment regarding its external protagonism.
\end{abstract}

Keywords: rising countries; think tanks; Brazil; United States-Brazil relations

\title{
Resumen
}

Los think tanks estadounidenses y la producción de ideas sobre Brasil como país emergente, 20002016

El artículo analiza las representaciones producidas por los think tanks estadounidenses sobre Brasil entre 2000 y 2016, un período de mayor protagonismo externo brasileño y cuya proyección internacional representó un desafío epistémico para el establishment de Washington. Para ello, se plasmó el panorama institucional en el que se articuló y difundió esta producción ideacional en Estados Unidos, y se empleó la metodología de análisis de contenido para investigar estas publicaciones y las entrevistas realizadas a actores que operan en este entorno. Se argumenta que esta producción alimentó una narrativa de valores compartidos en la que Brasil actuaría de manera convergente con Estados Unidos al compartir los costos de mantener el orden en regiones como Sudamérica y África Occidental. Sin embargo, la disidencia sobre el principio de soberanía y el papel de los BRICS y la retracción de la política exterior, acentuada por la crisis interna brasileña, también generó una narrativa que enfatiza la desconfianza en las capacidades brasileñas y la decepción por su protagonismo externo.

Palabras clave: países en ascenso; think tanks; Brasil; relaciones Estados Unidos-Brasil

\section{Résumé}

Les think tanks américains et la production d'idées sur le Brésil comme pays émergent, 2000-2016

L'article analyse les représentations produites par les think tanks américains sur le Brésil entre 2000 et 2016, période de plus grande importance extérieure brésilienne et dont la projection internationale représentait un défi épistémique pour l'establishment de Washington. Pour cela, le panorama institutionnel dans lequel cette production idéationnelle s'est articulée et diffusée aux États-Unis a été dépeint, et la méthodologie d'analyse de contenu a été employée pour enquêter sur ces publications et les entretiens réalisés avec les acteurs qui opèrent dans cet environnement. Il est avancé que cette production a alimenté un récit de valeurs partagées dans lequel le Brésil agirait de manière convergente avec les États-Unis en partageant les coûts du maintien de l'ordre dans des régions telles que I'Amérique du Sud et I'Afrique de l'Ouest. Cependant, la dissidence sur le principe de souveraineté et le rôle des BRICS et la rétractation de la politique étrangère, accentuée par la crise intérieure 
EDUARDO MUNHOZ SVARTMAN

brésilienne, ont également engendré un récit qui met l'accent sur la méfiance à l'égard des capacités brésiliennes et la déception quant à son protagonisme extérieur.

Mots-clés: pays émergents; think tanks; Brésil; relations États-Unis-Brésil

Artigo submetido à publicação em 5 de fevereiro de 2020. Versão final aprovada em 16 de setembro de 2021.

Opinião Pública adota a licença Creative Commons CC-BY. 